Article

\title{
Watson's Human Caring Theory: Pertinent Transpersonal and Humanities Concepts for Educators
}

\author{
Carey S. Clark \\ Nursing Programs, University of Maine at Augusta, 46 University Dr, Augusta, ME 04330, USA; \\ carey.clark@maine.edu; Tel.: +1-207-621-3466
}

Academic Editors: Sara Horton-Deutsch and Pamela Ironside

Received: 9 December 2015; Accepted: 7 April 2016; Published: 16 April 2016

\begin{abstract}
Jean Watson's Theory of Human Caring and the caring moment are based in part in the concepts of transpersonal psychology. This paper will provide a historical background around transpersonal psychology and how it relates to Watson's human caring moment. The purpose of explicating these humanities-based concepts is to support nurses and nurse educators in creating a deeper understanding of Watson's caring-healing moment as a time-space continuum, where the nurse's caring supports a mutually created environment for healing. The article provides useful background information, as well as outlining simple steps to revising nursing curricula so that they become supportive of nursing students' growth as transpersonal-caring beings.
\end{abstract}

Keywords: Jean Watson; human caring theory; transpersonal; nursing; theory; philosophy; humanities; pedagogy

\section{Introduction}

"Transpersonal refers to values of deep connectedness, of relationship, subjective meaning, and shared humanity ... Transpersonal conveys a connection beyond the ego, capturing spiritual dimensions all humans share with a deeper self, others, nature, and the universe." ([1], p. 13)

Jean Watson, nursing's living legend, began the development of the Theory of Human Caring/Caring Science over 35 years ago; since that time, the theory has evolved, and yet the concept of the creation of a transpersonal caring-healing moment remains as central to the core of both understanding and enacting the theory in nursing practice. This paper explores the history of transpersonal psychology (TP) and explicates how TP relates to Watson's theory, the human caring moment, and caring science. The reader is supported with a greater understanding of both the development of Watson's theory and the process of creating and experiencing the transpersonal caring-healing moment with patients. The reader is provided with guidelines for educators who desire to support students' capacity for growth in enacting transpersonal human caring states. The value of this work resides in the readers' capacity to explore the historical and humanities-based roots of Watson's human caring moment; in deepening our understanding of the transpersonal roots of caring science, nurses can strive to appropriately place the transpersonal aspects of human caring clearly within the realm of nurses' work.

Due to the heavy science-based curricula most nursing students experience, many nurses may struggle with the spiritual and humanities-based background necessary to unpack human caring theory in order to apply it at the bedside [2]. By taking a transdisciplinary exploration into the humanities-based field of TP, the nurse educator is afforded the opportunity to explore how TP theory and caring consciousness support the need for the paradigm shift beyond technical-medical 
approaches to nursing and nursing education, and toward the creation of a truly caring-healing transpersonal consciousness in nursing. Nursing students or professional nurses who are interested in creating a career based in healing-caring will benefit from this exploration. Additionally, nursing faculty can benefit from using the materials discussed here to support their own movement toward creating nursing curricula that truly enhance students' abilities to create caring-healing moments in practice settings.

\section{Transpersonal Defined}

The term transpersonal is defined as reaching beyond the personal realm or transcending the singular, personal state of being [3]. Transpersonal experiences are those types of experiences that require one to reach beyond, or transcend, the usual personal state of being; transcending the normal state of ego-and-body-bound experiences leads to the transpersonal non-ordinary state of consciousness that normally restricts and limits our perceptions of the world [3]. Walsh and Vaughn [4] defined transpersonal experiences as one's awareness of identity, or the self, as expanded beyond the singular being, with greater realizations of one's own interconnection with humankind, life, psyche, and the cosmos.

As Watson developed her theory of human caring, one of her original definitions of transpersonal was as follows: "Transpersonal refers to an inter-subjective human-human relationship in which the person of the nurse affects and is affected by the person of the other. Both are fully present in the moment and feel a union with the other. They share a phenomenal field, which becomes the life history of both and are co-participants in becoming the now and the future. Such an ideal of caring entails an ideal of intersubjectivity, in which both persons are involved" ([5], p. 58). While this aligns with other definitions of the transpersonal state, it also defines for us a key concept that should be held as one explores the transpersonal nature of human caring, namely that two persons are meeting as one, as equals, as involved deeply.

\section{Historical Roots of Transpersonal Psychology (TP): Humanistic Psychology}

During the late 1950s to early 1960s, humanistic psychology emerged as a remonstration against the dominant field of psychology with its reductionist view of the person as a mechanistic, behavior-based, stimulus-response creature [6]. The field of psychology at that time was dominated by behaviorism and psychoanalysis: behaviorism focused on conditioning, modification of behavior, and taming the person's innate biological drive, whereas psychoanalysis focused on the Ego learning to control the pleasure principle of the Id (Rowan).

Some of the originators of this seemingly radical new psychology included Abraham Maslow, Rollo May, Carl Rogers, Clark Moustaka, Alvin Mahrer, and James Bugental. Humanistic psychology called for the person to look deeply within the self, with the knowledge that self-awareness is requisite for self-growth. Self-exploration was seen as the first step toward maximizing one's evolutionary potential as a human being. Contemporary methods of humanistic psychology may take many forms, including psychoanalysis, group work, psychosynthesis of subpersonalities, dreamwork, meditation, yoga, tai chi, counseling, psychotherapy, drama therapy, and energy work [6].

Humanistic psychology set the stage for the emergence of TP and even today the aforementioned humanistic psychological practices, which support self-reflection and personal evolution, help one to become more integral and authentic, preparing one to access the higher levels of consciousness required for transpersonal states [6] According to Maslow [7], prior to one self-actualizing, one must first come into one's own authentic self; it is this authentic self that can move forward toward entering into the higher levels of consciousness and transpersonal spiritual ways of being.

\subsection{Transpersonal Psychology Emerges}

In the late 1960s, the field of TP evolved from its roots in humanistic psychology, with its foundational concepts arising from the work of William James, Carl Jung, Abraham Maslow, and 
the Asian contemplative traditions [8]. A number of humanistic psychologists (including Abraham Maslow, Stanislav Grof, and Antony Suitch) met in 1967 with the purpose of creating a new psychology that would build upon humanistic psychology and also honor an entire spectrum of human experience and capacity, inclusive of "non-ordinary" states of consciousness [9].

Of importance to nursing and the concept of the caring-healing moment, it should be noted that TP is concerned with exploring non-ordinary states of consciousness, by moving beyond the ego and the body boundaries, with the understanding that these states of consciousness encapsulate heuristic, transformative, healing, and evolutionary potentials [9]. In transpersonal non-ordinary states, the spiritual realms of reality can be experienced in ways that are as real or convincing as ordinary consciousness; studies have shown that these transpersonal states as spiritual experiences can be validated through consensus. In other words, when a transpersonal experience happens, both or all parties involved recognize this experience as a different state of consciousness from ordinary consciousness, and that the transpersonal experience has an inter-connected spiritual context beyond the normal boundaries of ego [9]. Hence, in nursing, a transpersonal caring-healing moment would have a state of consciousness that could be categorized as out of the ordinary, as determined by the consensus between the patient and the nurse. The transpersonal caring-healing moment is a sort of deep, intentional, consciousness-based caring that the nurse calls forth in conjunction with the patient's willingness to move into this healing space that is created during the transpersonal experience.

It is important to note here also what is not the essence of transpersonalism. Transpersonalism is not a religion or spiritual practice, though issues of spirituality and spiritual experience are at the forefront of the TP movement [10]. Transpersonalism is not "new age," though it does represent a paradigm shift in thought, science, culture, and consciousness. While metaphysics are important in TP, multiple ways of knowing are also honored as one considers intuition, contemplation, and integrative awareness [10]. TP provides us with a way of considering how we can learn to care deeply, creating nursing interactions that are meaningful for both the patient and the nurse.

This deep caring that emerges in a transpersonal human caring moment aligns with what many have felt as a nurse; to support others on their healing journey [11-13]. "Transpersonal refers to values of deep connectedness, of relationship, subjective meaning, and shared humanity. Transpersonal caring-theory makes intentionality, as focused caring-healing consciousness, more explicit" [1].

\subsection{Transpersonal Psychology Influences on the Human Caring Moment}

Watson's theory [14] was historically influenced by many philosophers and thinkers; some important influences on Watson's work were directly related to the transpersonal philosophers Abraham Maslow, Carl Rogers, and Pierre Teilhard de Chardin. The following section will briefly review the works of these TP pioneers in an effort to enhance the understanding of how TP history and development relates directly to Watson's human caring theory development.

\subsubsection{Abraham Maslow}

While Abraham Maslow was considered to be the father of humanistic psychology in the 1950s, he also helped create the framework for TP as noted previously. Maslow's initial predominant focus in psychology was on abnormal psychology, and Maslow was conversely drawn toward the positive aspects of human nature and the human potential [15]. Maslow proposed that humans can move toward their greatest potential, or self-actualization, through progressing up through a hierarchy of needs, from the basics of physiological needs toward security needs, social needs, esteem needs, and eventually self-actualizing needs.

In her work Nursing: The Philosophy and Science of Caring, Watson [14] clearly stated her alignment with Maslow's hierarchy of needs. One of her greatest recognitions was that when nurses treat patients as individuals and provide assistance with gratification of needs, and the patient feels recognized, appreciated, and loved, the patient will have more energy to move up the hierarchy toward self-actualization. Furthermore, she posited that self-actualization needs can and should be 
addressed by nurses, as "meeting only lower order needs may not help a person toward optimal health. Attention must be given to higher order needs" ([14], p. 109); and addressing these higher ordered needs equates movement toward optimal health. Watson [14] viewed higher ordered needs as intrapersonal-interpersonal, and the practice of caring in nursing has a social and human responsibility to promote higher ordered growth in oneself and in others. In many ways, this idea of supporting others toward self-actualization and wellbeing aligns with the idea that in order to create transpersonal states of human caring, the nurse must also be on his/her own healing journey [13].

\subsubsection{Carl Rogers}

Though Carl Rogers is usually classified as a humanistic psychologist, his work created a good portion of the groundwork for the emergence for TP. Watson has clearly stated that Rogers' work influenced her development of the Theory of Human Caring, as did Pierre Teillhard de Chardin $[14,16]$. Rogers was a psychologist who expanded upon Maslow's work with the idea that for individuals to grow or evolve, they require an environment of genuineness, acceptance, and empathy; additionally, he believed that there was only one human motive and that is to move toward self-actualization or fulfilling one's highest potential of human-beingness [17].

Rogers' work focused on self-development, and he postulated that all people have an innate tendency toward self-actualization as a fully functioning person; however, the person must as a child have a foundation of unconditional positive regard (approval and love regardless of behavior) coupled with positive self-regard [18]. The fully functioning person (which Rogers stated is not every person) is open to new and expanding experiences and has depth of reflective and emotional capabilities [17]. The fully functioning person is flexible, adaptive, spontaneous, intuitive, and creative, with a capacity for being fully present from moment to moment. At this level of development, the person relies on experience and trust of feeling as guides through life.

Rogers further postulated that humans' "phenomenal field" is inclusive of all experiences available at any given time, inclusive of both the conscious and unconscious [17]. The self develops via interactions with others [18] and it is this interpersonal relationship capacity that creates the platform for the transpersonal relationship as the person moves toward self-actualization. Rogers [17] created a person-centered form of psychology, based on the therapist's ability to be empathetic and help the person to become aware of their own goals.

Watson [14] cited that Rogers' idea of congruence relates to the caring nurse's authentic presence, openness, and a genuineness stemming from the ability to be real, honest, and authentic. This sort of genuine nature that is an aspect of transpersonal states is based in greater part around one's self-knowledge and openness to one's own feelings [14] A certain level of self-reflection and self-inquiry is needed for the nurse to impart genuineness and congruence extending beyond the usual narrow limitations of the professional role of the nurse, in order to create the sort of caring-healing atmosphere where the transpersonal caring experience is actualized [14].

Empathy is another of Rogers' transpersonal concepts that Watson viewed as key to developing the sort of healing-trusting relationships that the caring nurse strives for. Empathy is defined as the ability to sense the inner world of another and this also requires that the nurse be aware of his or her own inner world, creating a common emotional meeting ground. While one cannot completely undertake another person's life experiences, tuning into one's own experience with hurt, anger, sadness, guilt, joy, love, etc. creates a capacity for the nurse to become sensitive to another's emotional state and needs [14]. When one becomes truly empathetic, there is a level of non-judgmental acceptance around the often "uncomfortable" patient emotional states the nurse might encounter, such as anger, fear, discomfort, or conflict. This empathetic acceptance, paired with what Rogers and Watson [14] called non-possessive warmth (the unconditional, non-paternalistic positive regard expressed through non-verbal and verbal means) and congruence create the sort of nurse-patient trusting relationship that allows for the truly transpersonal states of caring consciousness to emerge. 
Rogers' influence in Watson's work is clear as we consider Watson's idea of an interconnected phenomenal field that is transpersonal in nature; within this unified field is where the human caring moment occurs. Watson considers transpersonal caring to be the effort beyond the ego, to meet and embrace the spirit or soul of the other, and the nurse's focus is on creating the space toward healing [19]; one can clearly align this healing encounter with Rogers's work and the idea of supporting the patient's movement toward self-actualization. "Transpersonal caring not only allows for release of emotions and the evolution of the person's spiritual self or soul, but it promotes congruence between the person's perception and experience, and promotes self as is, and ideal-self, and harmony within the person's mind, body, and soul. The process allows the self to reflect the self back on the self" ([14], pp. 70-71). Transpersonal human caring consciousness states such as this facilitate healing, greater self-awareness and knowledge, and therefore support of the patient's process of moving toward self-actualization.

\subsubsection{Pierre Teilhard de Chardin}

De Chardin was both a scientist (he was a geologist and a paleontologist, and he studied evolutionary sciences) and a theologian (he was a Jesuit priest). De Chardin focused on inter-relating science and faith and he proposed that, from an evolutionary perspective, we as humans are moving toward higher forms of consciousness, with the person becoming ever more aware of the self, and also aware of our interdependence with the whole of the universe [20]. As we evolve toward greater complexity and an expanding consciousness, we further recognize our interdependence and inherent connections with others.

In Watson's work, she stated that in the transpersonal caring moment, the nurse attempts to enter into, and stay within, the other's frame of reference in order to connect to the inner life world of the other, while recognizing the self in in others [19]. This connection allows the nurse and patient to create a mutual search for meaning, a sense of wholeness, and possible transcendence of suffering. This process aligns with de Chardin's work around evolution and consciousness, as well as coming to know oneself and others better. Watson clearly stated that it is through our interconnections that we grow and evolve: "we learn from one another how to be human by identifying ourselves with others, finding their dilemmas in ourselves. What we all learn from it is self-knowledge. The self we learn about, is every self. It is universal-the human self. We learn to recognize ourselves in others ... (it) keeps alive our common humanity and avoids reducing self or other to the moral status of object" [14].

Of great importance to the transpersonal state of human caring is Watson's [5] understanding that while our bodies are confined in an apparent time-space continuum, the mind and soul have the capacity to transcend time and space as we spiritually evolve; de Chardin was a proponent of this notion of the boundless nature of our spirits and consciousness. Additionally, much of Watson's current emphasis on love as caring can also be traced in part back to de Chardin and the idea that we need each other in loving and caring ways, but that the love and caring starts with the self first: "We need to love, respect, care for ourselves, and treat ourselves with dignity before we can respect, love, and care for others and treat them with dignity" [5].

The human caring theory that Watson proposed some thirty years ago continues to evolve today toward caring science status, with much of its roots based in TP. While human caring theory grew from humanistic philosophy, it now has moved toward the idea of human caring science. How do transpersonal states continue to align with the evolving and emerging science of human caring?

\subsection{Transpersonal States and Caring Consciousness: Relationship to Intentionality}

One of the key concepts that Watson [1] mentioned in discussing intentionality and transpersonal states is the need for differentiating between intentionality and "setting an intention." With intentionality, we strive to be with and cooperate with the emerging field before us, rather than trying to manipulate or change it, and to align one's consciousness toward caring-healing presence with the patient. In this way intentionality aligns itself more with love and acceptance versus the nurse's agenda for what needs to be done or shifted. Perhaps the simplest way of understanding 
this concept is that creating a transpersonal caring consciousness is done through a mind-body-spirit commitment toward entering into a transpersonal space with the other in a way that honors them, conveys compassion, and is reverent, loving, and authentic [1].

It is this conscious commitment that leads to development of the authentic transpersonal caring-healing space. The results of such intentionality-based interactions are a greater integral awareness of oneself and a greater understanding of the sometimes mysterious and awe-inspiring spiritual nature of the relationship between self, other, world, and cosmos [21]; therefore, human transcendence, despite illness and suffering, becomes possible [1]. This understanding and transcendence happens both with patient and nurse as they meet in the intentional transpersonal caring space. In this way, nursing practice can become truly spirit-filled, as spirits meet in this space, where the creation of room for universal-life energy that supports healing emerges.

From describing this sort of transpersonal, caring-healing, authentic, intentional nursing practice, I know intuitively and from my own experiences with this type of practice that what is being described is the art of healing, and the core of true nursing. I know as well that because today we are embedded in the allopathic system of cure, we as a profession need to find our way back toward our deepest desire to create nursing practice as a caring-healing endeavor. Students and nurses convey to me that they struggle to create the sort of caring-healing environment based in transpersonalism that Watson [1] described, and I believe we are obligated to support their growth in this area. Knowing the history of transpersonal states, the philosophical underpinnings of the theory adds value to the understanding of the type of human caring Watson is calling for.

\subsubsection{Supporting and Teaching Transpersonal Caring}

Firstly, we know that nurses who struggle to create and work in caring environments, and nurses who are under stress and become skills-task focused, are more likely to suffer from stress and burnout syndromes, and ultimately leave the profession [13]. We may intuit, and also continue to study, how nursing attracts the wounded healer in need of healing; therefore, our academic and workplace settings need to support nurses' skill development with their capacity to create caring-healing environments. Watson's theory application through transpersonal human caring states that, application of the ten caritas processes offers nurses and patients the opportunity to increase satisfaction in meaningful ways.

\subsubsection{The Other, Interdependence, and Caring}

To be in a transpersonal caring experience, the nurse and patient recognize and experience the reality of the interdependence and the deeper level of interconnectedness. Through interconnectedness, a foundation of reaching the other's life-world experience is built; this requires the nurse to be aware of his/her own existential-ontological foundation. The capacity to reach out to the other's (patient's) life-world during the transpersonal caring moment requires a unique level of awareness [22]; this transpersonal awareness may be considered to support the knowledge of self and other as the knowledge of common humanity: "This connectedness with other ... helps us to stay connected with the human spirit, helping us to avoid reducing the human being to an object, separate from spirit of self and from the spirit of the wider universe" ([16], p. 117).

What stands in our way of realizing interconnectedness through the transpersonal caring moment in nursing? As we have acknowledged, as a profession, caring is being shunted to the fringe of nursing practice $[11,12,16,22]$. What remains valuable to the majority of healthcare facilities where nurses practice nursing is the accomplishment of skills and tasks; this is reflected in some facilities striving toward using scripted discourses to support nursing as caring [23], versus supporting nurses in applying theories like Watson's, which requires a deeper level of connected authenticity than a script can provide. In order for transpersonal caring to become a reality, healthcare facilities must support transpersonal caring work through paradigm shifts in the workplace environment [23].

When scripting is used, the nurse may be encouraged to spend a few minutes listening to a patient and to perhaps reach out and provide connection through touch; however, scripting does 
not support the nurse in creating a space for the unique human experience to emerge [23]. Scripting does not support the skills it takes to be authentically present to meet the other in a field of caring consciousness. It flatly fails to support the nurse in creating a caring consciousness and intentionality toward wholeness of the transpersonal caring moment, which is literally beyond the "interpersonal" communication techniques that scripting calls for.

Interdependence is a key concept that should guide transpersonal human caring practices. Our belief systems, worldviews, and spiritual perspectives align to support our ability to create these meaningful and transformative interactions with others [16]. Watson related intentionality to her transpersonal caring process, basing the idea in quantum theory concepts. Quantum theory suggests that our separateness is one way to view our reality, but when our consciousness is viewed as an energetic potential, connecting consciousness with another person's consciousness is always a potential. Watson clearly stated that in order to enact transpersonal states, one must hold a sense of unitary consciousness as the worldview and cosmology; human caring requires the worldview that all beings are interconnected [16].

\section{Intentionality}

Intentionality is an important concept to both understanding and enacting transpersonal caring. However, it is also a concept that is often confused with simply setting a mental goal. When we consider intentionality in nursing and transpersonal states, we begin to see how intentionality is the act of using consciousness to directly and indirectly influence the individual and collective wellbeing [16].

Zahourek [24] further defined intentionality for healing practice, clearly stating that intention is different from and greater than intent and intention. Intentionality derives from the essence of our being and the capacity for intentionality evolves over time, and it focuses on and directs consciousness. Intentionality becomes the basis of transpersonal practices as it supports the capacity for perception and making meaning: "In healing, intentionality is a capacity; an energetic potential and a source of information. It is the capacity to create and modify intention" ([24], p. 43). When we enter into transpersonal caring states, the driving force of this process could be considered to be intentionality.

\section{Transpersonal Human Caring Practices: What Needs to Be Taught and Supported through Caring Science Approaches}

We know that people learn through experience; it is therefore posited that without personal experience with transpersonal states, nurses and nursing students cannot hope to actually enact transpersonal states of human caring in the workplace. The good news is that nurse educators can implement and value the transpersonal experience within curricula. Educators can begin by enhancing or building their own personal transpersonal experiences, and then moving toward supporting this experience with students in academic and clinical settings.

\subsection{Students}

Senior nursing students want more than just support with growing their technical skills: they desire assistance with developing deeper relationships with staff, support with learning how to interconnect with patients, and greater comfort levels with taking on the role of self as nurse [25]. Students feel more successful and express greater levels of satisfaction when they are supported in using holistic-caring modalities to support their role development [26]. Moreover, learning to relate to others by creating transpersonal human caring states can be part of this process. In my own conversations with Jean Watson she has made me keenly aware that we all want and need to experience this sense of interconnection that is the transpersonal caring consciousness state, whether we can consciously recognize this drive or not. 
"Transpersonal caring competencies are related to ontological development of the nurse's human competencies and ways of being and becoming; thus "ontological caring competencies" become as critical in this model as "technological curing competencies" were in the conventional modern, Western nursing-medicine model". ([19], paragraph 11)

This quote reminds educators that we need to find ways to support, assess, and evaluate student growth around their transpersonal caring competencies. Students need to learn what the caring competencies are, and how to apply Watson's ten caritas process through the creation of transpersonal states. While some nursing programs may teach about the caritas process, they may end up missing the necessary requirement of transpersonal capacity as requisite to the human caring moment experience.

To prepare oneself to enter into transpersonal states, a strong practice of self-reflection and self-care is needed. This aligns with Wilber's integral approach to evolution of consciousness states, and curricula can be developed to support student growth in this area [27].

\subsection{Faculty}

"Professional socialization, self-actualization, self-fulfillment, and self-concept are affected by interpersonal relationships, interactions with others, and the ability of the nursing instructor to meet the students' learning needs. Caring attitudes, demonstrated by an admired, respected instructor who acknowledges students' strengths and weaknesses, are significant to students' lives and their learning. Caring is as central to the teacher-student relationship as it is to nursing ... Caring must be enacted in order for it to be experienced and learned". ([28], p. 194)

The idea of creating a caring curriculum is not a new one; works such as those by Bevis and Watson [28] and Hills and Watson [29], support nursing faculty in moving in this direction through a precise curricular and faculty development processes. However, many nursing curricula remain focused on content delivery and demonstration of skills, as opposed to supporting the human development of nursing students [13]. As nursing faculty, we should be keenly aware that we need to move away from forced lecture-based curricula and over-emphasis on technical skill acquisition, while heeding the call toward more applied, reflective, and experiential learning [30]. Nursing faculty should be exhibiting and modeling caring behaviors and transpersonal connection in our interactions with students. With the type of caring curriculum development espoused by Bevis and Watson, coupled with new and innovative approaches toward education and the caring presence of faculty, faculty can create opportunities for students to develop and refine their human caring and transpersonal skills, while growing in their experiences related to nursing as a caring science. We must learn to openly value the self-care and reflective efforts of our students; this can be done in part by expressly valuing these efforts in our grading process and awarding credit for students' efforts toward the evolutionary consciousness [27].

More than likely, most nursing faculty have already had some experience with transpersonal states, including: experiencing deep love and connection with a loved one, moments of serenity or peace, mystical spiritual experiences in nature or with community, awareness or subtle energies, feeling creatively inspired by something beyond the self, meditative experiences, deep states of relaxation, sacred or spiritual experiences, and psychedelic states [30]. Some faculty may even share these experiences informally in clinical settings or as part of classroom content. Transpersonal practices may include meditation, study of scriptures or other spiritual teachings, rituals, visualization techniques, creative or artistic work, body and energy work, prayer, contemplative practices, compassionate service and action, transpersonal psychotherapy or counseling, yoga, and being present in nature [30]. In nursing education, we can align these actions with supporting students' self-care efforts; we must overtly value the types of self-care that further one's evolutionary processes and wellbeing, while creating a canvas for transpersonal experiences to emerge. 
On many levels, as nursing faculty, we are ethically obligated to role model our own healing and self-care processes for those we teach [13]; and if we are ethically committed to supporting nursing students in creating transpersonal human caring interactions, this role modeling of self-care and evolutionary growth toward transpersonal states is a requisite. It is essential that nursing faculty attempting to teach and role model transpersonal human caring have transpersonal practices, experiences, and skills in place that support this process.

We can begin to include transpersonal experiences and awareness in our curricula in ways that support students' gaining experience with the modalities that support transpersonal states, and then truly valuing these experiences in academia. A simple way to do this is to start and/or end each class or clinical meeting with a guided imagery or meditation experience. Through these practices, students learn to experience the relaxation response, and faculty role modeling of transpersonal states can occur.

Students can also undertake other simple exercises during class time, such as sitting quietly, focusing on the heart, and listening to a classmate's experience without talking or commenting on the topic. Having done this with students in the past, allowing each partner the opportunity to speak and then to listen from the heart, they often struggle with their own thoughts while listening, and how to express caring and presence with the one they are working with while not speaking. This provides the educator an opportunity to support learning around techniques to create transpersonal spaces and define how transpersonal practices can strengthen the students' abilities to listen and be present. These efforts may support the need for the student to regularly practice quieting their own minds and coming into the present moment. Distance or online students can practice this with patients, colleagues, or loved ones.

Additionally, while it may seem a bit radical at first in that it departs from the concept of grading tests and papers, by providing opportunities for graded reflective experiences as related to the experience of transpersonal states, we begin to value the art of caring in our curricula and we can use the reflective process as a means to support transpersonal experience and growth in caring capacity with our students [27]. Benner et al. [31] recognized this need for creating reflective practitioners, and it is also part of the process of learning how to enter into transpersonal human caring states. There are many reflective tools to support students' increasing their awareness and experience with their own healing journey and transpersonal states. For instance, in a holistic-integral curriculum developed for an RN-BSN program, educators use texts such as Richardson's [32] Extreme Self Care and Borysenko's [33] Fried: Why You Burn out and How to Recover as ways to guide the self-care journey and reflective practice that leads toward healing and the ability to be more present with what matters. These exemplar texts also support students in better understanding themselves and their interconnection with others, part of the process and skill set needed to create transpersonal states.

\subsection{In Clinical and Sim Lab}

Clinical settings are often very stressful for students, from being victims of horizontal violence to learning new and often invasive technological skills. These settings also create the opportunity for students to learn and grow in their experience with meeting caring competencies. The educator can act as a role model for this process, but it should be made clear to the student what the instructor has done before, during, and after the role modeling experience; discussing openly with students helps them to also reflect on what they witnessed or co-engaged with. It also may allow the instructor to further model transpersonal states as he or she cares for the student during the reflective process.

Clinical pre-conference can start with a short meditation, guiding students toward the process of intentionality that they will enact during the day. Students can be given tools and tips to help them return to the caring-healing process through the day, such as returning to intentionality while washing hands, taking breaks for rest and rejuvenation, pausing to breathe deeply before entering a room, sitting down with patients and listening from the heart, offering healing forms of touch, and/or returning to the heart space throughout the shift. Students can create a card, or carry a special 
touchstone, which can be placed in their pocket and used as symbol or reminder to come into caring consciousness space throughout the day.

Watson Caring Science Institute [34] also has a tool available that students, patients, and instructors can use to evaluate caring competencies exhibited. This simple tool asks patients to rank their experience with the caregiver in the competencies of delivering care with loving kindness, meeting basic human needs, developing helping-trusting relationships, creating a caring-healing environment, and valuing the patients' personal beliefs and faith (see Watson Caring Science Institute [34]). This tool could be adopted to become part of the student evaluation process, whether evaluation is supported with patient input, instructor observation, and/or student reflection on these competencies.

In simulation experiences, students can be evaluated for their caring presence either through self-evaluation and/or by "patients," staff, other students, and/or faculty. Faculty can also participate in this process by role modeling transpersonal caring states during the simulation exercise and supporting students with the reflective process during debriefing, which should include reflection on the process. How did they prepare to enact the transpersonal state prior to the exercise beginning? What tools did they use to remember to return to the transpersonal human caring consciousness throughout the process? What could they do differently next time?

Another innovative idea is to take some clinical time and devote it toward transpersonal exercises. This could be a special caring retreat-type day, or woven into the clinical, simulation, or lab experiences.

In light of the challenges of adding to already full nursing curricula, one may consider that the suggestions made in this article to include tools and skills to support student's growth enacting transpersonal states in the human caring process become threaded throughout curricula. The simple shifts mentioned here require more of a change in perspective, inclusion of reflective pedagogical approaches, and a mindset shift in contrast to a complete major revision of curricula. Some schools are already having success with this process [27].

\section{Conclusions}

The history of Watson's transpersonal human caring moment as based in transpersonal psychology (TP) provides educators and nurses with a basis upon which to build their understanding of the transpersonal nature of human caring consciousness. With this renewed or deeper understanding of the meaning of human caring, nurses, nursing students, and educators can be supported and motivated in their efforts to teach, learn, and experience transpersonal states.

Transpersonal skills are needed to create the sort of deep interconnected human caring that Watson has called for in her theory. As educators of future nurses, if we care for our students, if we want to be the true advocates of the healing potential of caring, if we follow our calling toward caring and healing, we are therefore inclined to support students in learning how to interconnect with others through transpersonal processes and to enact Watson's theory at the bedside. The suggestions in this article are just the beginning to how we can support students in learning about transpersonal states and creating caring-healing spaces that are requisite to enacting Watson's theory.

There are many questions to be researched and answered as we strive to build a body of evidence around caring science in nursing. Can caring be "taught" or is it supported through experiences? How is caring facilitated by nursing faculty? How do nurses learn to care for patients more deeply through shifts in consciousness? How do/can healthcare systems support nurses in enacting transpersonal human caring states? What are our ethical obligations as educators to support nursing students in their endeavors to care for patients in ways that create sacred meaning to the art and science of nursing care? Finally, how do reflective self-care and healing experiences support the nurse's ability to enact transpersonal states at the bedside?

Conflicts of Interest: The author declares no conflict of interest. 


\section{References}

1. Watson, Jean. "Intentionality and caring-healing practice: A practice of transpersonal nursing." Holistic Nursing Practice 16 (2002): 12-19. [CrossRef] [PubMed]

2. Sourial, Sarah. "An analysis and evaluation of Watson's theory of human care." Journal of Advanced Nursing 24 (1996): 400-4. [CrossRef] [PubMed]

3. Grof, Stanislav. Psychology of the Future: Lessons from Modern Consciousness Research. Albany: SUNY Press, 2000.

4. Walsh, Roger, and Frances Vaughan. “On transpersonal definitions." The Journal of Transpersonal Psychology 25 (1993): 199-207.

5. Watson, Jean. Nursing: Human Science and Human Care, a Theory of Nursing. Norwalk: Appelton-CenturyCrofts, 1985.

6. Rowan, John. Ordinary Ecstasy. The Dialectics of Human Psychology, 3rd ed. Philadelphia: Taylor \& Francis, 2001.

7. Maslow, Abraham. Toward a Psychology of Being, 2nd ed. Princeton: Van Norstrand, 1968.

8. Rothberg, Donald. "Ken Wilber and the future of transpersonal inquiry: An introduction to the conversation." In Ken Wilber in Dialogue: Conversations with Leading Transpersonal Thinkers. Edited by Donald Rothberg, and Sean Kelly. Wheaton: Quest Books, 1998, pp. 1-29.

9. Grof, Stanislav. "Brief history of transpersonal psychology." International Journal of Transpersonal Studies 27 (2008): 46-54.

10. Daniels, Michael. "The transpersonal self: A psychohistory and phenomenology of the soul." Transpersonal Psychology Review 6 (2002): 17-28.

11. Clark, Carey S. "The nursing shortage as a community transformational opportunity." Advances in Nursing Science 25 (2002): 18-31. [CrossRef] [PubMed]

12. Clark, Carey S. "The nursing shortage as a community transformational opportunity: An update." Advances in Nursing Science 33 (2010): 35-52. [CrossRef] [PubMed]

13. Clark, Carey S. "Stress, psychoneuroimmunology, and self-care: What every nurse needs to know." Journal of Nursing and Care 3 (2014): 146. [CrossRef]

14. Watson, Jean. Nursing: The Philosophy and Science of Caring, 2nd ed. Niwot: University Press of Colorado, 1985.

15. Cherry, Kendra. "Biography of Abraham Maslow." 2015. Available online: http://psychology.about. com/od/profilesmz/p/abraham-maslow.htm (accessed on 12 January 2015).

16. Watson, Jean. Postmodern Nursing and Beyond. London: Harcourt-Brace, 1999.

17. Rogers, Carl Ransom. "A theory of therapy, personality, and interpersonal relationships, as developed in a client centered framework." In Psychology, a Study of Science. Edited by Sigmond Koch. New York: McGraw Hill, 1959.

18. Pescetelli, Dagmar. "An analysis of Carl Rogers' theory of personality." 1996. Available online: http:// pandc.ca/?cat=carl_rogers\&page=rogerian_theory.com (accessed on 2 December 2015).

19. Watson Caring Science Institute. "Caring science theory and research." 2015. Available online: http://watsoncaringscience.org/about-us/caring-science-definitions-processes-theory/ (accessed on 2 December 2015).

20. Henderson, Charles P. "God and science: The death and rebirth of theism." 1996. Available online: http:/ / www.godweb.org/godand.htm (accessed on 3 December 2015).

21. Smith, Marlaine C. "Caring and the science of unitary human beings." Advances in Nursing Science 21 (1999): 14-28. [CrossRef] [PubMed]

22. Ranheim, Albertine, Anita Kärner, and Carina Berterö. “Caring theory and practice: Entering a simultaneous concept analysis." Nursing Forum 47 (2012): 78-90. [CrossRef] [PubMed]

23. Hogan, Kay. "Caring as a scripted discourse versus caring as an expression of an authentic relationship between self and other." Issues in Mental Health Nursing 34 (2013): 375-79. [CrossRef] [PubMed]

24. Zahourek, Rothlyn P. "Intentionality forms the matrix of healing." Alternative Therapies 10 (2004): 40-49.

25. White, Ann H. "Clinical decision making among fourth year nursing students: An interpretative study." Journal of Nursing Education 42 (2003): 113-20. [PubMed]

26. Woodward, Wendy. "Preparing a new workforce." Nursing Administration Quarterly 27 (2003): $215-22$. [CrossRef] [PubMed]

27. Clark, Carey S. "Beyond holism: Incorporating an Integral Approach to support caring healing-sustainable nursing practices." Holistic Nursing Practice 26 (2012): 92-102. [CrossRef] [PubMed] 
28. Bevis, Em, and Jean Watson. Toward a Caring Curriculum: A New Pedagogy for Nursing. Sudbury: Jones and Bartlett, 2000.

29. Hills, Marcia, and Jean Watson. Creating a Caring Science Curriculum: Emancipatory Pedagogies for Nursing Education. New York: Springer, 2012.

30. Daniels, Michael. “Transpersonal FAQs." 2015. Available online: http://www.transpersonalscience.org/ tranfaq.aspx\#Q3 (accessed on 1 December 2015).

31. Benner, Patricia, Molly Sutphen, Victoria Leonard, and Lisa Day. Educating Nurses: A Call for Radical Transformation. Stanford: The Carnegie Foundation for the Advancement of Teaching, 2009.

32. Richardson, Cheryl. The Art of Extreme Self-Care: Transform Your Life One Month at a Time. Carlsbad: Hayhouse, 2009.

33. Boryesenko, Joan. Fried: Why You Burn out and How to Revive. Carlsbad: Hayhouse, 2011.

34. Watson Caring Science Institute. "Watson Caritas Patient Score." 2015. Available online: http:// watsoncaringscience.org/watson-caritas-patient-score/ (accessed on 1 December 2015).

(C) 2016 by the author; licensee MDPI, Basel, Switzerland. This article is an open access article distributed under the terms and conditions of the Creative Commons Attribution (CC-BY) license (http://creativecommons.org/licenses/by/4.0/). 